\title{
Entertaining International Visitors-The Hybrid Nature of Tourism Shows
}

\section{Chris Ryan (Professor of Tourism) \& Ayse Bas Collins (Assistant Professor)}

To cite this article: Chris Ryan (Professor of Tourism) \& Ayse Bas Collins (Assistant Professor) (2008) Entertaining International Visitors-The Hybrid Nature of Tourism Shows, Tourism Recreation Research, 33:2, 143-149, DOI: 10.1080/02508281.2008.11081301

To link to this article: https://doi.org/10.1080/02508281.2008.11081301

$$
\text { 曲 Published online: } 12 \text { Jan } 2015 .
$$

Submit your article to this journal

цll Article views: 89

Citing articles: 14 View citing articles $\square$




\title{
Entertaining International Visitors - The Hybrid Nature of Tourism Shows
}

\author{
CHRIS RYAN and AYSE BAS COLLINS
}

\begin{abstract}
Given that a post-modern perspective of tourism has introduced a new gaze of the destination as a construction of both visitor perception and supplier commodification, the language of cultural compression and place displacement has become commonplace. It has almost become a cliché to argue that tourism deconstructs history, fact and fantasy to re-assemble a hybrid that nonetheless can generate an experiential authenticity. Yet the tourism academic literature has been comparatively silent about the construction of theatre entertainment for visitors outside of a critique of indigenous peoples' cultural performance. This paper examines the ways in which a Japanese venture based upon Dutch architecture seeks to entertain an audience that is a mix of domestic and international visitors through an evening theatre entertainment titled An Eastern Odyssey. The nature of plot and presentation is examined in an effort to develop a set of reference points to illustrate how a cast comprising primarily non-Japanese performers develops a story with a mix of reference points as diverse as Gilbert and Sullivan to Star Wars via the Japanese tradition of Kabuki in order to overcome language differences and incomprehensibilities. It is argued that constructed reference points produce a show that communicates over cultural distances by reference to a hybrid of popular cultures. Yet, this hybrid is itself a package distanced from the cultures of its audiences by bridgeable nuances to develop a touristic dramatology of fantasy and spectacle. Within a trilogy of fantasies, production, the nature of Huis Ten Bosch and arguably a financial fantasy, An Eastern Odyssey becomes itself a metaphor for much post-modern tourism.
\end{abstract}

Keywords: tourist experience; dramatology; tourist theatre; Japanese tourism.

\section{Introduction}

Sasaki (2002), writing of multi-culturalism and theatre on university campuses, decries discourses of consensus that emphasize a seamlessness that subsumes differences and assumes stable identities. She argues that it is better to recognize difference wherein it is possible to contest dominant narratives and thus discover new ways of relating to each other. Armstrong (2005) writes of a performance pedagogy and drama wherein the individuality of actors' voices are retained in an exploration of the intersection of their identities, and describes what she terms 'coalition space' or the 'space of authoring' (Armstrong 2005:202). This paper utilizes these concepts in an examination of an entirely different form of theatre, that of the entertainment of international audiences divided by language and culture in a setting of place displacement. It, therefore, postulates a hypothetical intentionalism as against a possibly different actual intentionalism that is not uncommon in literary or artistic interpretation (Dillworth 2005) where, for example, we are unclear as to what possibly, say, Shakespeare wrote, but through the interpretation of a director (or in this instance the academic observers) a hypothetical intention assumes meaning to (hopefully) if not shed light at least impose a thought about a specific performance and its wider context.

The purpose of this paper is to analyse the performance An Eastern Odyssey, which was produced at Huis Ten Bosch in Sasebo, Japan, in 2003. The production serves as an example of entertainment produced for international audiences who lack a common language and where the use of translation services are not logistically possible and would arguably detract from the enjoyment. But it is also argued that such a production is multi-nuanced, and thus the paper is located within a triad of fantasies. There is, first, the fantasy of Huis Ten Bosch itself as a replica of things Dutch in Japan. Second, there is the fantasy of a dream overcoming financial caution to produce bankruptcy, from which the Park wants to arise, phoenix like. Third, there is the fantasy of the production itself - located in Japan, aimed at an international audience within which Japanese visitors will be a possible majority, based in spectacle but with nuances of Kabuki, Star

CHRIS RYAN is Professor of Tourism at the University of Waikato Management School, Private Bag 3105, Hamilton, New Zealand. e-mail: caryan@waikato.ac.nz

AYSE BAS COLLINS is Assistant Professor at the Department of Tourism and Hotel Management, Bilkent University, 06800 Bilkent, Ankara, Turkey. e-mail: collins54@hotmail.com 
Wars and Laurel and Hardy. These three fantasies may be interpreted as a metaphor for tourism, for it is argued that in our understandings of tourism it may be necessary to employ an ontology of art (Thomasson 2005).

\section{The Location}

Its Nature

The location of the study is Huis Ten Bosch, located near Sasebo (itself about 45 minutes drive from Nagasaki) in southern Japan. As shown in Figure 1, Huis Ten Bosch is a representation of, if not Amsterdam, then at least of things Dutch. The theme park opened in 1992 on the island of HarioJima in Omura Bay, Nagasaki-ken. It covers an area of about 1.52 million square metres (approximately 376 acres) on which 40,000 trees and 300,000 flowering plants were planted. Additionally, over six kilometres of canals were dredged, forming a waterway within the park to connect it with the harbour. In common with about 40 per cent of The Netherlands, the complex is built on reclaimed land. Huis Ten Bosch (which means "House in the Woods") is the name of the Dutch Royal Family's residence, and a replica of the Palace stands within the centre of the complex.

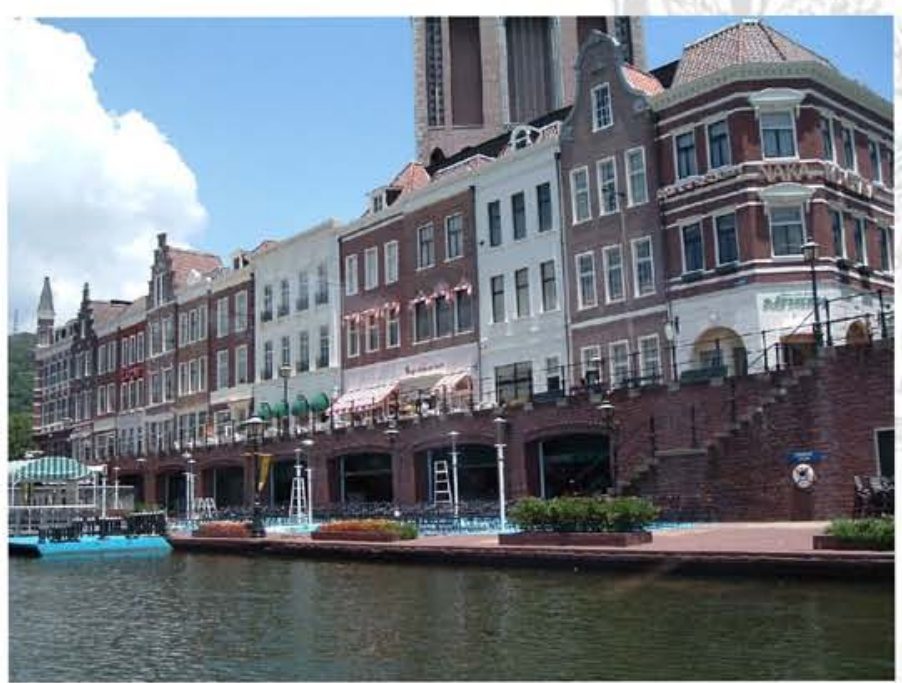

Figure 1. Huis Ten Bosch Canal Side (Photograph reproduced by courtesy of Chris Ryan)

The theme park was the dream of one individual, Takekuni Ikeda. Ikeda was a navigation office badly burnt and scarred during the battle for Okinawa in April 1945. Fortunately, he made a full recovery and after the war went to university, subsequently becoming a successful architect responsible for many of Japan's major buildings, including the Keio Plaza Hotel and the Mitsui Building in Tokyo. He designed the park and in 1992 it opened at a cost of 2.1 trillion yen. Much of the site had been an industrial infill that had lain derelict for several years. As noted, both fresh water ponds and salt water canals were constructed and plantings included oaks, walnut, chestnut, horse chestnut, camellia, arbutus wild strawberry trees, Chinese hackberry, holly, paulownia, magnolia, laurel, planes, mountain cherry, rhododendrons and others (Blazdell 2006). These lakes and woods quickly became home to over 30 species of birds and 70 species of insects by the time Huis Ten Bosch opened. By 2005,61 species of birds and 150 species of insects, including a butterfly on the Environment Ministry's endangered species list, had been identified at the site (Nicol 2005).

\section{The Finances}

The park and supporting infrastructure, including sewage disposal, was built to the highest standards available at that time. Unfortunately, by the time of its opening in February 1992 Japan's miracle economy of the post-war years had burst and was about to enter a period of prolonged stagnation. The park was unable to service the interest on debt capital in spite of high initial visitation figures. Indeed, by the mid-1990s the Park was attracting well over 3 million visitors per year, and at its peak attracted 3.8 million visitors. By the end of the decade, however, the park faced considerably more competition from two sources. First, more Japanese citizens were travelling abroad for their holidays, and thus a replica of an overseas destination had less appeal, especially that perhaps of which Japanese had comparatively little knowledge. Possibly more significant was the opening of other theme parks. For example, Disney had immediate access to the Tokyo market and was able to generate a 95 per cent repeat visitor rate, something that had eluded Huis Ten Bosch. A third factor was Huis Ten Bosch's failure to sell condominiums associated with the development, partly because of initial high prices but also because of commuting distance from the main source of local employment in Nagasaki, which is about an hour's drive away. Consequently, in February 2003 Huis Ten Bosch filed for court protection from creditors under the Corporate Rehabilitation Law, leaving 230 billion yen in debts. It was not alone in its financial troubles. Immediately prior to this, two other parks, Seagaia in Miyazaki Prefecture and Gulliver's Kingdom at the foot of Mount Fuji had also filed for bankruptcy.

In December 2003, Nomura Principal Finance Co., an investment arm of Nomura Holdings Inc., signed an agreement to rescue the bankrupt theme park operator after both the Tokyo District Court had granted its request for revival and a long investigation into the theme park's facilities had been undertaken. The new CEO, Takeuchi, concluded that Huis Ten Bosch was not just a theme park, but a 'unique facility with no other model in the world' (Japan 
Times 2004). The decline in visitor numbers had stabilized by 2004. In July 2004, Nomura Principal Finance Co. announced the purchase of 160,000 shares in Reorganizing Company Huis Ten Bosch to the value of 8 billion yen, with new shares being issued in March 2005 for a further 1.5 billion yen while a further share issue was planned for March 2007 for the same amount. One major advantage of the reorganized company has been the abolition of past debt. Nomura estimates that with the current capital structure and admission combined with hotel revenues, a visitation of approximately 2,200,000 visitors a year will generate profits for the complex. Three factors indicate that this target will be achievable. First, prior to the take-over in 2003 the numbers of visitors, while they had declined in recent years, were still close to the 2,000,000 level. Second, the Japanese government launched a new campaign to attract foreign tourists; the first time it had seriously considered marketing Japan to the overseas market. Third, the continued growth of the Chinese outbound market and its proximity to Japan was perceived as a new opportunity. The injection of new capital and the removal of past debt have meant significant change for the resort, and in 2005 and 2006 several new projects were announced to develop the entertainment within the resort. In 2006, the company hoped to return to profitability. It also plans to pay off about 20 billion yen in debts by 2015 with help from Nomura Principal Finance. This last is not only important financially, but also symbolically in a society where bankruptcy incurs social opprobrium and it has been suggested to the authors that this is also a factor that holds back recovery in the domestic market (Cooper, pers comm. 2003).

\section{The Dutch Theme}

It might be queried, 'Why the Dutch theme?' Nagasaki possesses a historical link with The Netherlands since April 19, 1600, when a Dutch ship, the Liefde (Dutch for Charity or Love), arrived in what is now known as Usuki Bay in Kyushu with a crew of 23 Dutch sailors and an Englishman, Will Adams, all under a Portuguese captain, Quackernaeck - the sole survivors of an initial crew numbering 110. Adams was able to win the confidence of the shogun, Tokugawa Ieyasu, overcoming the objections of the Portuguese who had been the first Europeans to land in Japan in 1543 and who had denounced the Dutch as pirates. The arrival set in motion the establishment of the Dutch East India Company (Burns et al. 1993). In 1637, an exclusive trade arrangement between Japan and the Dutch East India Company commenced that would last for nearly 250 years. In essence, the Dutch took over most of the Portuguese holding throughout the trade routes, were shrewd traders and thus prospered from the trade (Wallbank 1964). Much of this was centred on the tiny, artificial island of Deshima constructed in 1636. Its permanent staff numbered about 11, including its director, and usually two ships a year arrived from The Netherlands. On arrival, the Japanese confiscated the sails and these were returned only when the vessel was ready to sail, or permitted to sail. The staff were not allowed to set foot on Japanese soil, although Japanese workers helped service the small colony. Given that, except for one short period from 1817 to 1821 , the population was wholly male, the local museum in Nagasaki notes that informal relations with local Japanese women did occur. The only time the Dutch were permitted on Japanese soil was the occasion of their showing homage to the shogun every two years or so in a big, formal and costly procession to the court in Edo (Tokyo). They were able to sustain favour with the Japanese through a number of means, even including the import of exotic animals such as elephants and camels as gifts for the shogun. This arrangement was sustained until the Treaty of Kanagawa in 1854 was signed when a US naval fleet under the command of Matthew Calbraith Perry (17941858) forced Japan to enter into negotiations with the US about opening the country for trade with the United States, and then subsequently with other nations, notably England, France and Russia. Another historical facet noted at the Deshima museum was that the port was the only sovereign Dutch land independent of the Napoleonic conquest of The Netherlands. It is this history that helps explain the context for a multi-themed play in a Dutch setting in Japan.

\section{Constructing a Performance}

While this paper will concentrate upon a live show, $A n$ Eastern Odyssey performed in 2003, in order to construct its performance pedagogies, it is suggested that the principles enunciated will, if anything, possess a continuing importance in illustrating the hybridity of performance tailored for international audiences not sharing a common language. Contrary to the pedagogy criticized by Armstrong, it can be argued that the objective of entertaining such an audience through a seamless performance that emphasizes collectiveness is a legitimate objective for a tourist company. The difficulties facing the company are obvious. Facing a multi-cultural audience any theatre production that depends solely upon the spoken word will face difficulties. Many in an audience will not understand the language, and even if they were to do so, the referent set might not be easily available to them. There are many responses to such a situation. Mime would be one. An alternative used by the example assessed here is the use of spectacle and action. Yet storyline still possesses importance.

In outline, the production, An Eastern Odyssey, is akin to pantomime. In classical style the story line flows from 'boy gets girl, boy loses girl, boy gets girl back again'. This, in and of its self, gives a multi-cultural audience comfort 
knowing that there is a familiar direction in which the story is headed. The beautiful princess Aurora falls in love with the dashing English captain, but is lusted after by the powerful vizier/magician, who seizes her to take her into his watery kingdom of Davy Jones' locker. A tearful and fearful father agrees to give the hand of his daughter to the gallant captain and in return the captain, accompanied by his comic sidekick and faithful servant, raise a crew to sail after the wicked vizier and regain the princess for the captain and her father. The captain accomplishes this after overcoming many difficulties and battles, including the need to gain a magic stone. The stone allows him and his servant to descend into the watery depths where, almost overcome by the forces of evil, he is able to destroy them with a gun powered by the magic stone regained from whence it had fallen by his sidekick in the proverbial 'nick of time'. All ends happily with the penultimate song a love duet as the couple embrace, and happiness is sure to follow. What follows is a song and dance number as all celebrate the safe return of the hero, the happy union of hero and heroine, and the thanks of a grateful father. Again a classical style is reinforced, 'Boy meets Girl, Boy loses Girl, Boy sings and dances and gets Girl back again: Musical'. Finally, fireworks are launched into the night sky where a laser beam plays through the swirling smoke to end the 45-minute production, thereby leaving the audience to make their way through the streets of Huis Ten Bosch back to their hotels. All live happy ever after!

So many clichés, though trite, they still serve to draw a multi-cultural audience into the experience.

All of this is staged upon a replica of 17 th century European sailing vessel of the type that sailed to Deshima, complete with gun deck and rigging. The cast is international in character, comprising primarily of Japanese, American, and European actors. With such a scant description it would seem that the production is wholly dependent on song, music and spectacle in order to entertain, but as in many instances the production is multi-layered with hidden nuances. In the first instance, it appears to have but a token Japanese cultural presence. The heroine, Princess Aurora, and her maidservant, her father and his court are Japanese. The rescuers are European, presumed to be Dutch, if we make the connection between Huis Ten Bosch and its past, and a villain whose character is a most ambiguous figure with overtones of a Disneyesque evil magician from Aladdin and combined with long whiskers of a 1920-30s Chinese villain from the black and white Hollywood films, perhaps even Ming the Merciless of the Flash Gordon Series. He is, of course, dressed in black (thus denoting evil or the dark side as seen in so many movies). The villainous magician through trickery averts an initial capture by casting a spell of confusion veiled in smoke and passes through a secret trapdoor by which he can escape but not before seizing the princess (ahh, shades of a thousand blockbuster movies, a 'damsel in distress', young and nubile, in a dire strait with a villain and requiring a hero to dash to her rescue). Who else could fill the bill for the rescue, but a group of swashbuckling buccaneers (how can one forget Pirates of the Caribbean). A little bit of this and a little bit of that, put it to music, voilá, we have a stage production!

Aside from the storyline, with a closer examination we find that the production does contain many Japanese theatre traditions derived from kabuki. Kabuki was a popular form of theatre said to have originated in the early 17 th century. The story goes that the art form was initiated by a female, Okuni, who took her form of dance from Kyoto. It originally flourished among the lower Japanese social class. The movement combined folk and religious dance, and ironically, although founded by a woman, within 30 years only male performers were allowed to appear in the kabuki roles. This was because the dance had taken on an association with prostitution. As an aside early Victorian music halls also enjoyed a similar mixed reputation due to their popularity with the lower social classes and the perceived 'looser morals' of the female performers that led to many liaisons with upper class males. They were drawn to the music halls due to their gaiety and the thrill of "forbidden fruit" as "being naughty' that was frowned upon by a self-righteous respectable society. So too it was with kabuki.

The word kabuki itself is an aggregate of three separate terms ' $k a$ ' (meaning songs), ' $b u$ ' (meaning dance) and ' $k i^{\prime}$ (meaning skills). It blends to form a theatre of colour and spectacle comprising the elements of 'Story, Musical Elements, Dramatic Content, Dance, Costume, Make-up, Theatre Design, and Actor/ Audience Relationship' (Ritchie and Watanabe 1963; The International Society for Educational Information, Inc., Tokyo 2006).

While kabuki is a well-recognized art form in Japan today (and would appear to have little to do with the actual production at Huis Ten Bosch given that a kabuki performance would be performed in Japanese for a Japanese audience), nonetheless, there are traces of this tradition evident in the production. Apart from there being extravagant colours, beautiful costuming, a spectacle and numerous songs, all are combined in a story line. From the visual effect of kabuki the proscenium of the stage/set is lower and much wider than that of American and European theatres. Second, the stage has the appearance of a long rectangle instead of the nearly square form of theatres elsewhere. This, of course, 
equates well with the deck of a 17th century sailing vessel. Again, at Huis Ten Bosch, the stage is low when compared to the seating of the audience, who sit on tiered steps that run parallel to the stage. The play uses the full extent of the stage moving back and forth. Likewise, the shape of the stage and the movement of the characters upon the stage afford the audience to feel of a ship, even to include the roll of the sea as characters stagger in a storm sequence.

It can be objected that this congruence of tradition and performance may be simply little more than physical logistics, but other features are more strongly associated with kabuki tradition. A characteristic of kabuki is that it is an interactive theatre where direct appeal is made to the audience. The most traditional form of this is through the use of a narrator who speaks directly to the audience. By narration the audience is provided with the theme and setting. The producer can interject comment upon predicaments and outcome as they befall the characters in the play. This technique also allows the narrator to form blocks that signal the end of one act and beginning of another. The audience is informed at the beginning that this is a story of old Japan, of a time long ago (as if taken straight from Star Wars 'A long time ago, in a galaxy far, far away') - yet it could not have been more than 400 years ago given the introduction of European characters - but it is sufficiently long ago to permit different manners and dress. At each stage, the narrator, an 'old salt', muses on what the hero should do, and how might he find his way through the tasks befalling him (the familiar voice of Rod Sterling rings in the ear as if the Twilight Zone was only yesterday).

A third feature of kabuki is the use of the comic sidekick, often expressed through moments of clumsiness or carefully choreographed scenes of bending down at just the right moment so that enemy soldiers trip over a leg or a backside, but who nonetheless is plucky and faithful even as others may give way to despair or cowardice. This is not unique to Japanese theatre. So many teams fit into this style of acting, Abbott and Costello, Dean Martin and Jerry Lewis, Bob Hope and Bing Crosby, to name a few, but all associated with 'straight man comedy acts' and further all not uncommonly associated with the 'damsel in distress' (Eames and Abele 2004).

A fourth feature that is evident in the production is that of the kurogo, the man in black. Essentially, these are the scene shifters, the movers of props, and they too make their appearance in the production as chests are moved, fallen swords picked up and carriages moved on and off the stage. Moreover, in this instance, in the scene where our hero first finds himself in Davy Jones locker, a melding of traditions comes to the fore when techniques derived from Czech Black Theatre are used. Fluorescent fish swarm across the stage, a squid appears, and the fish dart and swim manipulated by the men (and women) in black who fade into indistinct shapes so that the audience is assailed by colour and lights to set the scene. They melt into the shadows and the colours feed our sensory perceptions and when combined with the storyline the humans no longer exist. This feature is common with kabuki, but has its European linkages also.

There are yet a number of other nuances and reference sets for a Japanese audience. Further, albeit thinner echoes of classical kabuki theatre exist - notably the Kanjincho (The Temple Offering List), Musume Dojoji (Maiden of the Dojoji Temple), and Takatsuki (The Clog Dance) which are dance dramas (or shosa-goto). In one scene the sailors recruited by the hero perform a song and dance routine with, at times, a staccato routine that to the authors' minds was redolent of a number of referent sets. Within a Japanese tradition of takatsuki the routine presented the same type of uniform sound associated with such dances. To a western contemporary mind the scene recalled any number of routines including for example, the song and dance routine set in Herod's court in the film and stage productions of Andrew Rice and Lloyd Webber's Jesus Christ Superstar. Additionally, reflective memories exist of West Side Story when one considers the responsive song and dance. Also, for a moment, the cadence of the song, to a British mind, contained overtones of a Gilbert and Sullivan chorus from HMS Pinafore. The words, a mixture of Japanese and English verse in such a routine become secondary to the nature of the dance action and rhythmic nature of the uniform stepping, and can thus appeal across many different reference sets to be appreciated as a routine in itself which was not foreign and could be easily assimilated into any number of neural reference sets.

Other references exist within contemporary Japanese and western theatrical traditions which remain interwoven with each other. The hero, Captain Jack (itself the name of a contemporary pop artist in Japan) is an action hero - a common theme in many films including the Quentin Tarantino favourite The Street Fighter. Released in 1974, this remains a popular blood and gore film in Japan, $X$-rated for its violence, yet which has been influential amongst the cognoscenti. The film was watched by Christian Slater in Tarantino's True Romance and its star, Sonny Chiba had a role in Kill Bill. But there are links with the older tradition of kabuki and this production which lies nuanced in the character of Ratnose, played in the film by Waichi Yamada. As the critic Sanjuro (2006) notes 


\begin{abstract}
But perhaps most importantly, The Street Fighter is unintentionally hilarious. The violence itself is pretty funny in a Wile E. Coyote sort of way, but Chiba's facial expressions mid-battle are an absolute hoot. He also seems to suffer from the worst asthma problems this side of Darth Vader, a habit which has been euphemistically called, 'redistributing his chi' $^{\prime}$
\end{abstract}

In film and stage production the role of the sidekick, as in classical kabuki, is to sustain action, provide the means of aid to the hero, and to provide a comic relief through action as outlined above.

One conventional aspect of kabuki is that of formalized acting, known as mie, which is assumed by the principal character. In this production this is assumed at various stages by Aurora herself, who represents the quintessential element of being Japanese through her dress, dance and stance; she is no Princess Leia from Star Wars, for she is the demure lady respectful of her father and his wishes even as he initially expresses doubts about her love for the English captain. Could one expect anything else given the timeframe depicted and the parental control and respect that, until only recently, were instilled within a whole society?

With reference to this interpretation there remains a further observation - the title with its use of the word odyssey: itself a word charged with cultural significance - a reference to Homeric Greece and a ten-year sea voyage and a love affair between Ulysses and his Penelope that survived trials far greater than those that befall the good captain and his Aurora in this production. Yet, apart from a nautical theme, for the authors of this paper there seemed, ironically little to sustain this reference to its Greek origins. Thus, within the referent sets of dialogues across spaces are the omissions and silences that in themselves help formulate the nature of the dialogue.

\section{Interpretation as Metaphor}

It can be objected that the nuances, references and linkages identified above would not be those of every member of the audience. To which it can be said - why should it be so? Does not every single member of the audience come to a performance such as this wishing to be entertained, to complete an evening of good food, drink and company to wander off to their hotel rooms to fall asleep within this fantasy of Holland in Japan, to wake the next morning to enjoy windmills, floodings, sea trips and other delights of the theme park. Tourism is part of the entertainment business - and at the heart of tourism lies not simply place, but experience of place, and possibly too the sharing of experience so as to add to, complement and fulfil the potentialities of the physical attributes of place to create authentic experiences (Wang 1999) and intimacies (Trauer and Ryan 2005).

An Eastern Odyssey can be seen as a metaphor for tourism, or at least some experiences of tourism. If we are to have an ontology of tourism, and even more particularly, an ontology of performance of place or theatre of place within tourism, then the traditional social sciences of mind-independent relationship may well lead us into cul-de-sacs of empirical positivism that say little, if anything, about tourist experiences of place. Classical social theory is about discovery of objects and relationship between measurable entities - but tourism, like performance, is not about artefacts independent of observers. Tourism is about action and engagement with place, not about having an independent existence oblivious to place. In the words of the dramatist - there are spaces to be crossed. Even reflection is a form of engagement. The producer of a production aimed at international tourists as is the case of An Eastern Odyssey is akin to any other producer, director or interpreter of place. All portray and place their own interpretations, directions and selective acts of production - but the totality involves the spectator as an actor in engagement with what is viewed - it is this actor's engagement that provides a meaning and purpose to that produced by the director and other actors. Thus, sitting in an audience comprising people drawn from many nationalities, located in a place that is a displacement of Amsterdam, Holland, to Amsterdam, Sasebo, in a location that arguably defied financial sense to fulfil a fantasy, watching a fantasy of old Japan in a musical production that ends with a laser light display amongst the smoke left by fireworks - such a tourist experience arguably defies an ontology that seeks to analyse tourism on the premise of mind-independence. If we are to understand the performance of tourism, and the collectivity of individualistic experiences on the part of an audience, then it becomes necessary to conceive of tourism and production on the premise of things in action within the mind of participants. As Dillworth (2005:249) notes

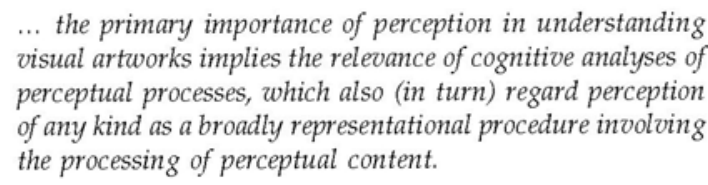

Except that here the authors would exchange the word 'context' for 'content' in that it is the layered nuances of a site and performance as described above that makes the experience of tourism so engaging and explicable only in non-functional and not wholly rational terms. There is a double coding within much of tourism. Just as An Eastern Odyssey can be described in terms of stylistic performance 
and story content, so (to cite again Armstrong 2005) across a coalition space of actor as performer and tourist as actor within the audience, there is a perceptual encoding and consequent decoding of reference sets on the part of the latter. An Eastern Odyssey possesses many reasons for interest - it is of interest in how a multi-national audience is entertained and engaged, it is of interest for reasons of its setting and how it alludes to a past based upon historical connection, and for its theatrical traditions, both common and specific; and finally it possesses interest as a wider metaphor for many of the characteristics of post-modernity that themselves are a feature of much of contemporary tourism.

\section{References}

ARMSTRONG, A. E. (2005). Building Coalition Spaces in Lois Weaver's Performance Pedagogy. Theatre Topics 15(2): 201-220.

BLAZDELL, P. (2006). Huis Ten Bosch. Japan Times Online available at http://www.bootsnall.com/articles/99-09/huis-ten-bosch-japan-september1999.html - Accessed on 23 May 2008.

BURNS, E., LERNER, R. and MEACHAM, S. (1993). Western Civilizations: Their History and Their Culture. New York. WW Norton and Company. DILLWORTH, J. (2005). A Double Content Theory of Artistic Representation. Journal of Aesthetics and Art Criticism 63(3): 249-260.

EAMES, J. and ABELE, R. (2004). The Paramount Story: The Complete History of the Studio and its Films. New York. Simon and Schuster.

JAPAN TIMES (2004). The Japan Times Online available at http://www.zoominfo.com/people/Takeuchi_Daisuke_557063711.aspx - Accessed on 23 May 2008.

NICOL, C. W. (2005). Going Dutch: A 'theme park' that's an eco-friendly dream. The Japan Times Online available at http://search.japantimes.co.jp/ cgi-bin/fe20041007cw.html - Accessed on 23 May 2008.

RITCHIE, D. and WATANABE, M. (1963). Six Kabuki Plays. Tokyo. The Hokusiedo Press (English translation).

SANJURO, K. (2006). Gekitotsu! Satsujin-ken (The Street Fighter) Pan Asia Review Archives.

SASAKI, B. (2002). 'Toward a Pedagogy of Coalition'. In McDonald, A. and Sanchez-Casal, S. (eds) Twenty-First Century Classrooms: Pedagogies of Identity and Difference. New York. Palgrave MacMillan: 31-59.

THE INTERNATIONAL SOCIETY FOR EDUCATIONAL INFORMATION, INC., TOKYO (2006). Available at http://historyofideas.org/japanese/ kabuki/kennelly-bunraku-kabuki.html - Accessed on 23 May 2008.

THOMASSON, A. L. (2005). The Ontology of Art and Knowledge in Aesthetics. Journal of Aesthetics and Art Criticism 63(3): 221-229.

TRAUER, B. and RYAN, C. (2005). Destination Image, Romance and Place Experience - An Application of Intimacy Theory in Tourism. Tourism Management 26(4): 481-492.

WALLBANK, T. (1964). Man's Story, History in its Geographic Setting. New York. Pearson Scott, Foresman.

WANG, N. (1999). Tourism and Modernity: A Sociological Analysis. Oxford. Pergamon. 